\title{
ARCHITECTURAL SOLUTIONS TO REDUCE THE EFFECTS OF SALT STORMS
}

\author{
Zahra Farzaneh $^{\star 凶}$ and Shabnam Akbari Namdar ${ }^{2}$ \\ ${ }^{1}$ PhD Student in Architecture, Department of Architecture, Tabriz Branch, Islamic Azad University of Tabriz, Iran \\ ${ }^{2}$ Assistant Professor, Department of Architecture, Tabriz Branch, Islamic Azad University of Tabriz, Iran
}

\section{Research Article \\ PII: S238315531900004-8}

Received: 22 Sep. 2019 Revised: 30 Nov. 2019 Published: 15 Dec. 2019

Corresponding author's E-mail: Iran.1z.farzaneh@gmail.com

\begin{abstract}
With an increased level of salty and saline land in the region around Lake Urmia followed by powerful winds and the creation of salt dust, the agricultural lands of the region progressively move towards salinization and eventually desertification. Environmental adverse effects of salt dust in the dried areas of the lake, which is the chief source of this problem, can be minimized by drainage. In more detail, by continual or sporadic flooding methods or by sprinkler irrigation and precipitation, soluble salts can be washed from saline soil profiles. Object-oriented image analysis (OBIA) techniques are one of the latest means of satellite image processing in the scope of remote sensing. These techniques have significant potential in soil science studies. The application of soil improvers to advance the physical and structural characteristics of the soil is quite common. This study is of review and descriptive type, and the collection of resources in this study was a library method and by reviewing Internet resources. The results of this research suggest relevant architectural and urban design solutions to reduce physical vulnerability to storms. In this respect, solutions have been given.
\end{abstract}

KEYWORDS: Salt Storm, Architectural Solutions, Soil Improvers, Climate

\section{INTRODUCTION}

Natural and synthetic processes are currently critical threats to aquatic ecosystems and objects. Mainly due to mismanagement of water use in the basin and reduced access to the lake, Lake Urmia, the world's second-largest salt lake in northwestern Iran, is drying up. The lake's water level has been declining rapidly since the mid-1990s. Meanwhile, the construction of fifty dams and diversion structures driving climate change, are the principal reasons for this. The creation of a 15-kilometer road in the middle of the lake's Street is another reason that stops the normal circulation in the lake. The situation has become severe over the past two decades, and the need for restoration is an essential priority for the region. The contribution of ten main rivers to pour into the lake is considered as the ultimate solution to this disaster. However, the biggest challenge associated with any restoration program is public awareness and information about environmental values. Environmental adverse effects of salt dust in the dried areas of the lake, which is the chief source of this problem, can be minimized by drainage. Hitherto, drainage has only meant discharging excess water from the ground. Obviously, this has been done in dry and semi-arid regions, along with the extraction of excess salt from the soil. Salinity and wetlands are related phenomena.
Near the year, phenomena influence the movement of water in the soil and are a function of factors such as climatic conditions and soil characteristics [1]. Optimization of saline soils usually starts with the downward displacement of accrued salts on the surface, and the restoration of these soils by interruption of capillary ascent flow has also been studied [2].

In developed countries, due to the attention of these countries to environmental protection and the existence of governmental and non-governmental institutions, the destructive effects of human activities and environmental degradation are low and limited. These environmental harms and damages happen in different manners in different environments such as seas and lakes, jungles, cities, villages, and other spaces. Meantime, the elimination of water resources (sea, lake, swamp, river, spring, etc.) due to the direct dependence of human life on them and the preparation of human water needs, are of supreme importance. Wetlands are worthy ecosystems that have a broad variety of functions among many types of natural ecosystems. In addition to protecting biodiversity, they further have multiple other natural, economic, and social values. Economic researches prove that a wetland has about ten times the economic value of forests and 200 times the economic value of arable lands [3]. 


\section{Lake Urmia and its environment}

It is the twentieth largest lake in the world and the second after the Dead Sea in terms of salinity. Its maximum depth is 16 meters, and its average depth is 5 meters. The average length of this lake is about $140 \mathrm{~km}$, and its width is between 16 and $63 \mathrm{~km}$. Also, its approximate volume is estimated at 31 billion cubic meters. The water of this lake is chiefly fed by 14 permanent rivers including Zarrinehrood (41\%), Siminehrood (11\%), Godar (8\%), Barandooz (6\%), Shahrchai (2\%), Nazlouchai (6\%), plus 7seasonal rivers, 39 flood streams, springs within the lake, and direct rain and snow. The lake was registered on the UNESCO World Heritage List (1967). It is also registered as one of the international wetlands (registered in the Ramsar Convention) [4].
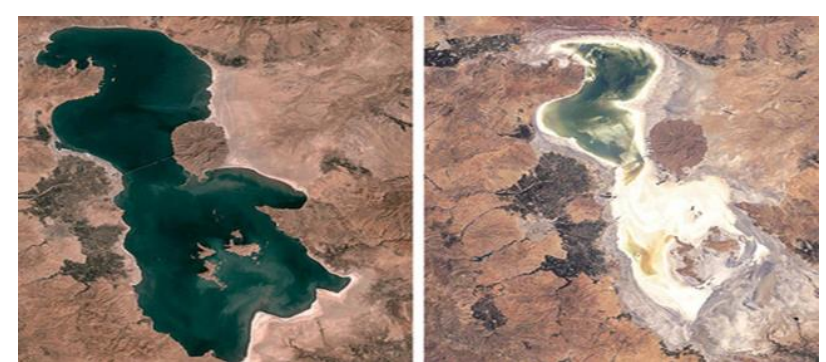

Figure 1. Urmia Lake

Urmia Lake is one of the most important international wetlands that has come to the brink of elimination in recent years for many factors, including the implementation of development projects. The adverse situation of Lake Urmia began a decade ago and is getting more critical day by day. Insofar as with this current trend, the possibility of total drying in the Urmia Lake in the following few years is not far from expectation. Lake Urmia's basin has been suffering droughts and consecutive dryness for at least a decade. Also, this basin is located in the construction place of different water structures in the form of dams, dikes, and bridges. These dams have been built without consideration of the copious droughts and lakes. This has led to the expansion of agriculture in the upper reaches of the rivers. Because of natural and man-made factors, this upstream prosperity has born the gradual drying up of the lake. The consequences of this problem in the succeeding few years will display in the form of disturbance of biological foundations in the area, urban and rural settlements, salinity of agricultural soils, and the emergence of one of the dust centers in the northwest of the country [5].

Considering the high biodiversity and the presence of different habitats in this basin, it can be assumed that this area is one of the most significant and affluent biological parts and natural ecosystems of the country. For this reason, the obligation to preserve natural habitats, not only in officially protected ranges but in the entire natural environment of Lake Urmia, which entails sensitive and vulnerable ecosystems, seems inevitable. These ecosystems are quite fragile and vulnerable to natural and synthetic changes. That is why making any environmental disturbance without factoring in the special features in them, will have a destructive and adverse result. If the ecological balance is upset, the reproducibility is very restricted, and it is quite challenging to return them to their original state. In terms of salinity, this lake has unique ecological and climatic conditions for the settlement of specific plant and animal species. Insofar as the development of valuable habitats in this area has improved biodiversity. Environmental standards, such as excess consumption of freshwater for agriculture in the coastal spaces around the lake, contamination of water and soil resources by many industrial pollutants, agriculture and urban wastewater and construction of a passageway in the lake, without evaluating the adverse environmental results, have altered the hydrological and hydrodynamic processes of Lake Urmia. The results confirm that if this trend remains without optimal environmental management, we will shortly observe the disappearance of ecological, economic, tourism, social, and aesthetic indicators of the lake. This is currently befalling with drought and human intrusion on the natural environment of the lake. Additionally, as a result of the interaction of increasing lake water salinity and overfishing, a large part of Artemia crustacean has been lost. These results are a serious alarm for the failure of maintenance management and unsustainable exploitation of worthy natural ecosystems of Lake Urmia.

\section{Population distribution of human societies and the development of polluting sources}

According to examinations conducted in 2007, the human population in the Lake Urmia basin was approximately 4913553 people. Of these, $69 \%$ lived in urban regions, and the remaining $31 \%$ dwelled in rural spaces. The higher urban population statistics show the huge capacity for changes in the ecosystem of the region by human and manufacturing factors. Because the quantity of pollutants in urban areas is more than in rural ones. Parallel with the event of drought, rapid, and uncontrolled population increase in arid and semi-arid zones is likewise one 
of the critical obstacles to achieving sustainable development. The impact of this factor on water resources management is also quite grave and alarming. Because on the one hand, it raises water consumption and water supply services and, on the other hand, because of increasing the volume of domestic and municipal wastewater and industrial process effluents and agricultural drainage water, it generates many problems and issues in managing environmental quality and especially sustainable management of water and soil resources [6].

\section{Pollution from port activities}

Other significant sources of pollution in Lake Urmia is port activities. There are major ports in Lake Urmia, the most important of which include the Sharafkhaneh port in Shabestar city, Golmankhaneh port on the west coast of Urmia (20 $\mathrm{km}$ from Urmia city), Rahmanloo port in Maragheh city, and Aq Gonbad port in Eslamy Island. Different activities in ports contaminate the water of Lake Urmia.

\section{The impact of salt dust and its environmental results}

The drought of Lake Urmia causes the precipitation of salt sediments and the rise of a suitable bed for the creation of dangerous fine dust during harsh storms. Considering that the direction of the prevailing winds in the region is in the direction of southwest, west, and southeast, the possibility of political-security damage to the coastal cities of the eastern to northeastern and even northwestern shores of Lake Urmia due to salt storms is very high. Field studies and conversations with the natives dwelling in the Gorchin Qaleh and Qal Qachi regions indicate the existence of this destructive phenomenon. Lake Urmia is the second most salt-saturated lake in the world. Supersaturated solutions are sensitive to the slightest changes. These solutions are converted to saturated solutions with the slightest change in conditions and precipitate huge quantities of solutes. This law of chemistry, with the least change in conditions, causes the deposition of various salts (gypsum and anhydrite - halite and Sylvite, Carnallite, etc.). This causes the precipitation of salt sediments in the lake bed. This phenomenon (salt precipitation) decreases the volume of the lake and regresses the waterline of the lake. Meanwhile, with this regression, saline areas with a deep salt layer (salt precipitation) expand. Based on the crystallographic system and mineralogical system,
As the salt dries when exposed to air at a pressure below the unit stability limit, the salt breaks down into a powder and disperses rapidly into the encompassing areas. The expanse of salt along with water, wind and other dispersing agents, on the one hand, causes the development of saline areas, and on the other hand, with the impact of salt on vegetation, animals and even humans, cause the loss and reduction of living conditions in the area. The expanse of the salt desert happens at a very high rate, and its influence on soil and the climate is much more critical than the impact of deserts in central Iran. The expansion of the salt desert by the salt storm resulting from the constant drying of Lake Urmia has the potential to destroy 1,200 square kilometers. Due to the crystallographic lattice and salty cleavage, this mineral is very easy to crush and powder. Following leaving the water, salt deposits are exposed to erosion and are moved as particles with the wind. Therefore, with the wind blowing, a salt storm forms in the area and affects a very broad area (around $1200 \mathrm{~km}$ ) in the shortest time. This transfer is reported to improve and expand the salt desert, hence destroying the biological system.

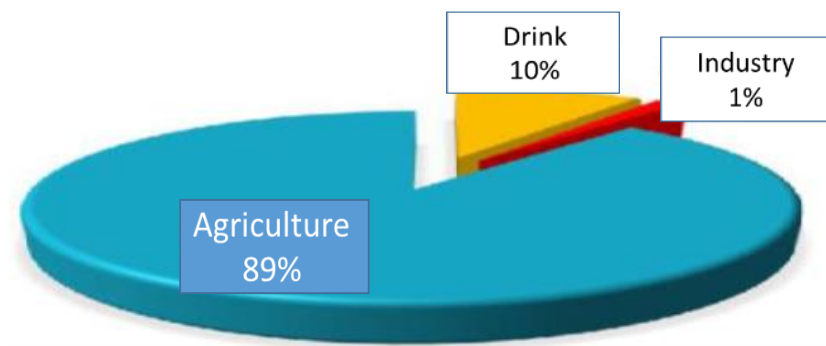

Figure 2. The volume of water consumption in various parts of Lake Urmia basin (http://ulrp.sharif.ir)

\section{Climate}

Surely, one of the most critical concerns following the regression and drought of a large part of Lake Urmia is becoming one of the active centers of salt dust in the area. The irreversible consequences of this matter will appear in the not too distant future. The figure displays areas of the country within a radius of $75 \mathrm{~km}, 100 \mathrm{~km}$, and 500 $\mathrm{km}$ from the lake. Regrettably, if this lake becomes one of the active centers of dust production, a notable population will be exposed to the menace of dust created by the drought of Lake Urmia [7]. Desertification is additionally one of the most critical dangers caused by the regression of a notable area of Lake Urmia. In fact, the hurtful experience of Lake Aral proves that the transformation of Lake Urmia into the desert of Urmia cannot be far from the expectation. 


\section{Winds}

Winds are one of the climatic factors whose direction, amount, and intensity are effective in climate change and precipitation. The maximum mentioned frequency of wind in Urmia station is $30 \%$, blowing from the west. Insofar as the west wind can be considered the dominant wind in the area. Winds blowing from the northeast, north, and southeast are in the next places in terms of wind frequency with $13.6,13$, and $10.7 \%$, respectively. Rainfall is normally concentrated in the months when westerly winds are prevailing. In spring, the intensity and span of winds are higher. Next, in summer, autumn, and winter, and eventually in spring, a relative balance is set between the east and west winds. Lake Urmia additionally helps to relocate surface masses by creating several breezes during the day and night. Particularly in mild and warm seasons, the impact of the lake in creating a breeze is more prominent. In fall, the direction of this relocation is east-west, while in winter, the wind blowing from the west is quite striking. In general, the main direction of the wind is from the west.

The local winds that blow in the Urmia area are as follows:

- Salmas winds: This wind blows in a north-south direction and in Urmia, it is known as Salmas (north) wind.

- White and black winds: blows in the opposite direction of the north-south wind and is known locally as "Aq Yel" (white wind).

- Land-sea breeze: This wind is sensible owing to the pressure difference between land and lake, and during the day, its direction is from the lake to land, while at night, it is from land to sea (Http://tarrahi1.blogfa.com/post/60).

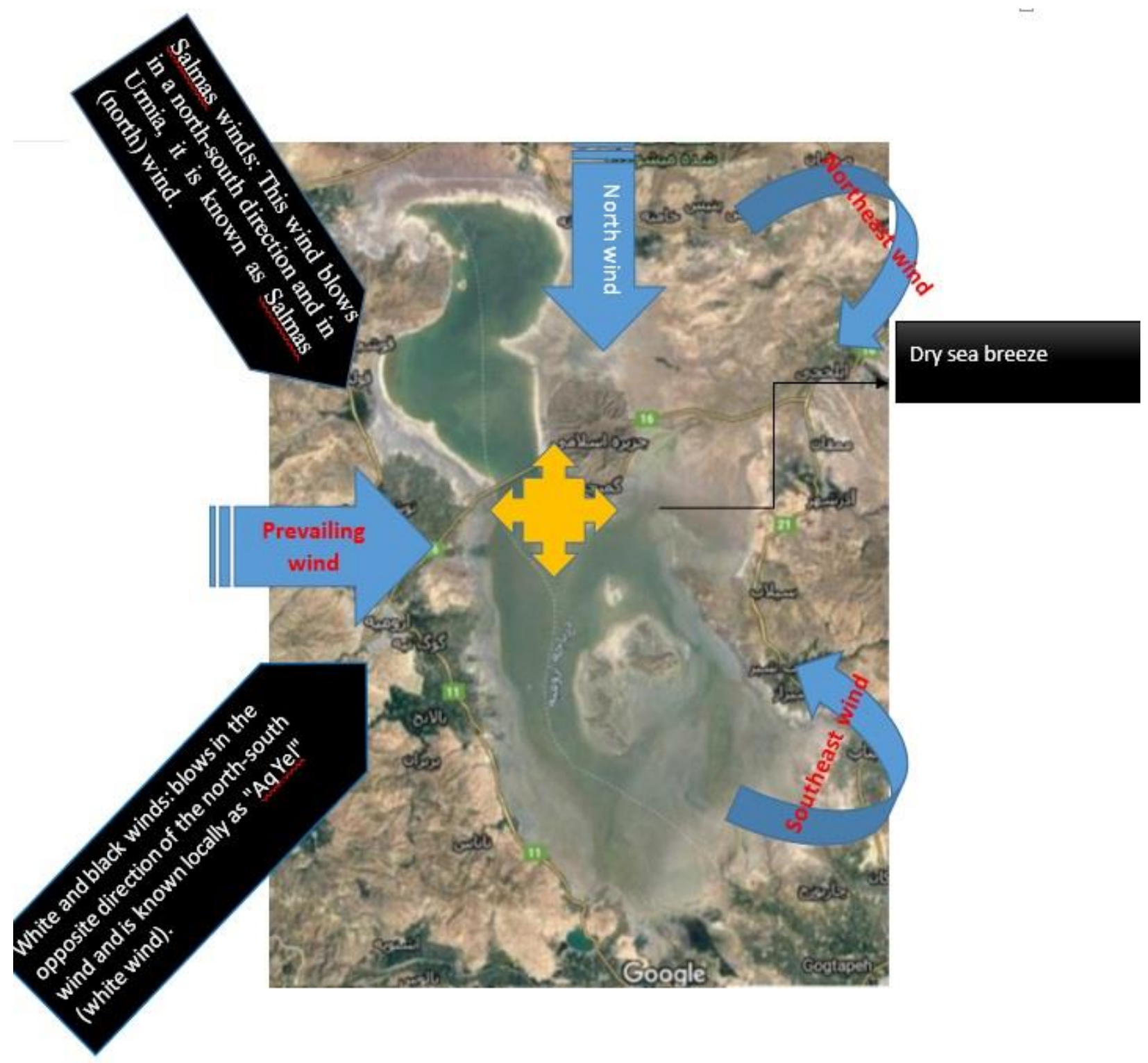

Figure 3. 


\section{Climate indicators}

Solar Index. is a coefficient based on which the amount of building use of solar radiant energy is defined (National Building Regulations of Iran, Article 19).

The effect of wind on the feeling of comfort. In general, wind can affect human comfort in open urban spaces in two chief ways. First, through the physical impacts it has on human activities and is made by wind pressure on the human body; And second, through the influence on the temperature sensed by the human body.

Beaufort Index. The wind changes the feeling of comfort by applying pressure and force to humans and things in the open air. In this case, the higher the wind velocity, the greater the pressure on humans and things. Thus, its effects on people's comfort will be different. In different countries, there are huge differences between the criteria used to estimate the tolerance threshold.

Penn Warden Index. examines the relationship between human thermal comfort and atmospheric factors such as wind, temperature, and radiation, along with human factors such as clothing and activity. Suitable and unsuitable winds of an area can be identified based on meteorological information of the area [7].

\section{The foremost reasons for the drying up of Lake Urmia}

The causes and outcomes of the destruction or drying up of lakes, which are mainly caused by human interference or natural elements, in many parts of the world are different. These consequences include economic, climatic, environmental, and recreational instability. Adverse consequences of this happening include population perils, biodiversity loss, illness spread, habitat loss, climate change, plant and animal population decline, and the like [8].

1- Absence of coherent planning program for the entire basin of Lake Urmia

2- Abnormal dam construction

3-Shahid Kalantari freeway in Urmia Lake

\section{Political-security outcomes of drying of Lake Urmia \\ Library findings \\ Salt storm threat. According to the} researches of Urmia Lake Revive Headquarters, the dryness of the lake engenders the precipitation of salt sediments and the formation of a suitable bed for the formation of hazardous dust during harsh storms. Owing to the prevailing winds in the region, which are in the southwest-west-southeast direction, the probability of harm to the coastal cities of the eastern to northeastern and even northwestern banks of Lake Urmia due to salt storms is quite high. The phenomenon of salt storms will further induce the destruction of agricultural lands and the incidence of diseases like asthma, cancer, etc.

Poverty and unemployment. Since the villagers are poorer and also do not have the required knowledge to deal with the threats due to lack of literacy, their vulnerability is higher. When confronting the crises, it is essential to be prepared and respond properly. In this regard, recognizing the current situation, identifying hazards, assessing risks, determining vulnerability, and intervening to lessen harm to communities is necessary. Because otherwise, the destruction caused by the disaster will increase promptly in the short term. According to the FAO, with the drying up of Lake Chad, fishing decreased acutely, and as climate change and its disastrous effects on agriculture in the region grew poverty and the spread of many diseases, people in the region were forced to move to other regions. It has also been determined based on comparative studies that the drop in the level of the Aral Sea has led to the elimination of fishing-related activities, and the drying up and abandonment of the ports of Moynaq in Uzbekistan and Aralsk in Kazakhstan. Further, the fishing industry in these two ports was demolished along with 60,000 jobs, incurring irreversible economic and social costs. Lowered economic activities in the region will raise unemployment, reduce the livelihood of indigenous peoples, and thus increase poverty.

Migration. Soleimani Ziveh [9]'s study in 2010 reveals that the drying of Lake Urmia induces the destruction of thousands of hectares of agricultural land in the region of this lake. The least consequence of this is the unemployment and migration of almost 3 million people in the provinces of East and West Azerbaijan.

Closing of conversion industries. A different study by Hesami and Amini [10] in 2016 explains that with the destruction of agricultural lands in the Urmia Lake basin, which happened due to the drying of deep wells in agricultural lands, the closure of 34 conversion factories in West Azerbaijan province alone will have irreversible effects in all areas of economic, industrial, social, and cultural, and will result in the forced emigration of villagers and marginalization around cities. 
Tourism: Numerous studies have been conducted about the impact of drying of Lake Urmia on tourism in this area, which indicates that the tourism situation is worsening with the drying of Lake Urmia. Asghari Sar-Eskalrood with the cooperation of other researchers in 2014 [10] claimed that in addition to the natural environment, the drying of Lake Urmia influences the economic and social environment of the region. Insofar as in recent years, the continuation of the upward trend of lake water depletion induces the destruction of resorts, recreational and household complexes, destruction of coastal infrastructure, unemployment of local citizens and migration of inhabitants of villages along the lake, reducing tourist arrivals, reducing income from the tourism industry and ultimately demand pressure on nearby destinations. With the regression of the water of Lake Urmia, investing in the tourism for this lake has faced difficulties, and the construction of seaside tourism facilities in this domain no longer makes sense.

Prevalence of different diseases: Comparative studies directed on dried lakes in the world and studies by researchers and Lake Urmia Rehabilitation Headquarters show that the spread of various illnesses in this area is probable with the drying up of Lake Urmia. Diseases include increased neonatal mortality, low birth weight, late pubescence, anemia, respiratory illnesses, immune system deterioration, neurological and behavioral changes, and infectious diseases. These investigations also prove the emergence of social anomalies, public distrust of government performance, difficulties in managing the regional space, and ethnic, tribal, and marginalization conflicts.

Table 1. Classification of influential variables based on experts' opinions

\begin{tabular}{ll}
\hline Index & \multicolumn{1}{c}{ Classification of the variables } \\
\hline Economic issues & Regional economy, regional employment, regional tourism \\
\hline Production area & $\begin{array}{l}\text { Agriculture of the region (agriculture and horticulture), industry of the region, livestock and } \\
\text { poultry breeding of the region, livestock and dairy products of the region, honey production } \\
\text { in the region, health of poultry and livestock of the region, emergence of new uses, salt } \\
\text { harvesting needed by industries }\end{array}$
\end{tabular}

\begin{tabular}{ll}
\hline Political issues & Political crises \\
\hline & $\begin{array}{l}\text { Agricultural soils, rangelands, salt storms, dust, quick sands, saline and non-saline dust } \\
\text { centers, water resources in and around the area (wells, springs, etc.), sunlight reflection } \\
\text { (albedo), light radiation, radiation from salts and elements, local climate, the dominant } \\
\text { ecosystem of the lake intrusion area, the ability of the area to become a national park }\end{array}$
\end{tabular}

\begin{tabular}{ll}
\hline Social issues & Health of local residents (physical, mental), local people, farmers community \\
\hline Residential system & Migration (village to city, out of province, etc.) Ruralization \\
\hline Major issues & Toxic compounds, food chain \\
\hline
\end{tabular}

Source: Research Findings (2017)

\section{The effectiveness of Gum Arabic and Use of Object-Oriented Fuzzy Technique in Improving Physico-Chemical Conditions of Saline Soils}

The use of soil improvers to improve the physical and structural characteristics of the soil is quite common. Gum Arabic improves soil's biological properties even in saline soils. Such that it increases the soil respiration from -67 to 275 (1-day CO2kg 2CO) in treated soils when the original respiration was 7 to 77 (MgCO2KG-1DAY-1). Gum arabic also developed the hydraulic conductivity of the saturated soils and decreased the acidity of the test soils. Soil salinity, as one of the global and critical perils in arid and semi-arid zones [4], is one of the most influential and effective factors on soil quality while it has no instantaneous and rapid effect [11]. According to researchers, soil salinity has been suggested as an abnormal environmental hazard due to its effects on human life [12].

But this working solution is limited because of the low quality of saline soils. Hence, other strategies to increase soil quality are needed to better establish vegetation. In applied agriculture, there are soil modifiers that improve soil physical condition by being added to the soil. Such substances are termed soil improvers. These materials can be synthesized or natural, organic, or inorganic. Other than enhancing the physical condition of the soil, natural polymers also add much nutritional value to the soil. 
Since they are natural, these materials can be more affordable than synthesized polymers [13]. Arabic gum, or acacia gum, is a hydrocolloid that produces a gelling property in the presence of water. It is a high molecular weight polysaccharide branched chain with calcium, magnesium, and potassium salts. This substance may be neutral or slightly acidic with a $\mathrm{pH}$ of 4.5-5.5 [13]. Because of the presence of hydroxyl groups in the gum and its hydrophilicity, it can condense viscosity or form a gelling or gel-like state in the environment it is present in [14].

Object-Oriented Image Analysis (OBIA) techniques are one of the new techniques of satellite image processing in the domain of remote sensing with significant potential in soil science investigations. In this respect, OBIA is recognized as a method that mixes the spectral and spatial pattern of satellite images to produce more accurate results. This method has been developed against basic pixel methods, which face a severe challenge of spectral property similarity. The chief objective of this research is to investigate soil salinity and apply a unified approach of object-oriented fuzzy to control land cover changes in the eastern bank of Lake Urmia, which has been influenced by salinity expansion.

\section{Control of salt dust particles by the non- biological method and by blending them with lime and clay}

Chlorides are prevalent in marginal areas. Because these substances are mainly of aquatic origin and are absorbed in large amounts of water. There are two main methods of penetration of these salts. One is through the ground and with the help of upward moisture in the walls. The other is through unwanted marine materials that are transported by the wind as a spray from the sea.

\footnotetext{
How to prevent this problem from occurring?

The first way is to use salt-free sand and cement and to use stones in a dry and mechanical manner. That is, to pin and screw the stone to the building surface. The second method is to use washed sand with less salt. Some cities in Iran have sweet soil. In fact, no matter how deep we dig, we will yet reach sweet soil. These types of soils contain the best sand and cement for facade construction. After working on your building stone, wash it twice with urban water at intervals of 7 to 15 days.
}

How to remove dandruff from stones and bricks

- Abrasion of the surface

- Hydrochloric acid

- Washing with water and brush

- Nano stone

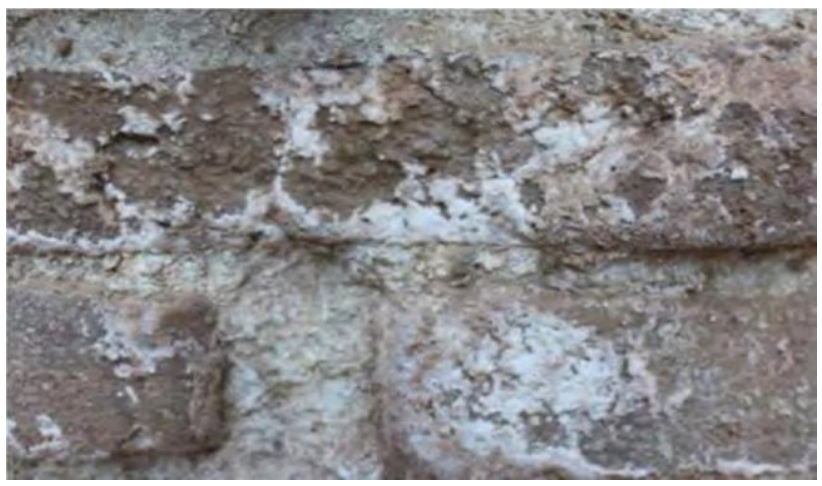

Figure 4. Dandruff formation and its mixture with lime and clay
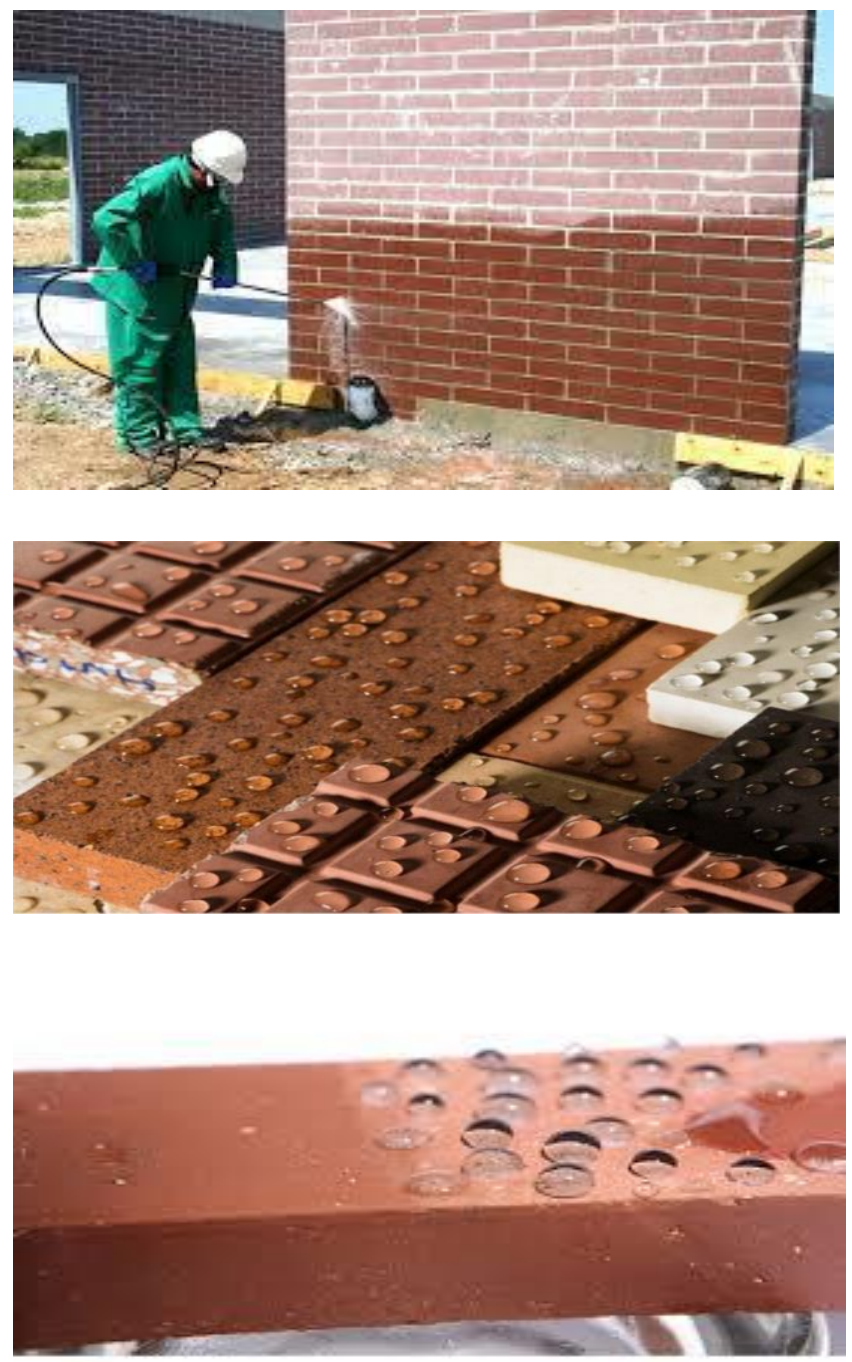

Figure 5. How to remove dandruff from stones and bricks 


\section{Introducing risk}

Tornado and Tropical Storms
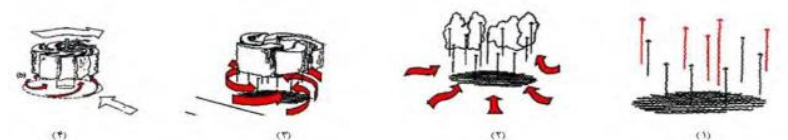

Figure 6. Stages of formation of tropical storms

\section{The effect of salt storms on buildings}

A tornado brings different destructions depending on its velocity. How powerful winds influence buildings depends on four factors: the situation of the building, the height and shape of the construction, and the location of the building relative to adjacent buildings. The wind force is essentially dynamic, but for simpler representation, it is used statically. Wind power distribution in buildings is in the form of steps and is always vertical to the surface [15].

The impact of wind on the body of the structure

The overall effects of wind on buildings are as follows:
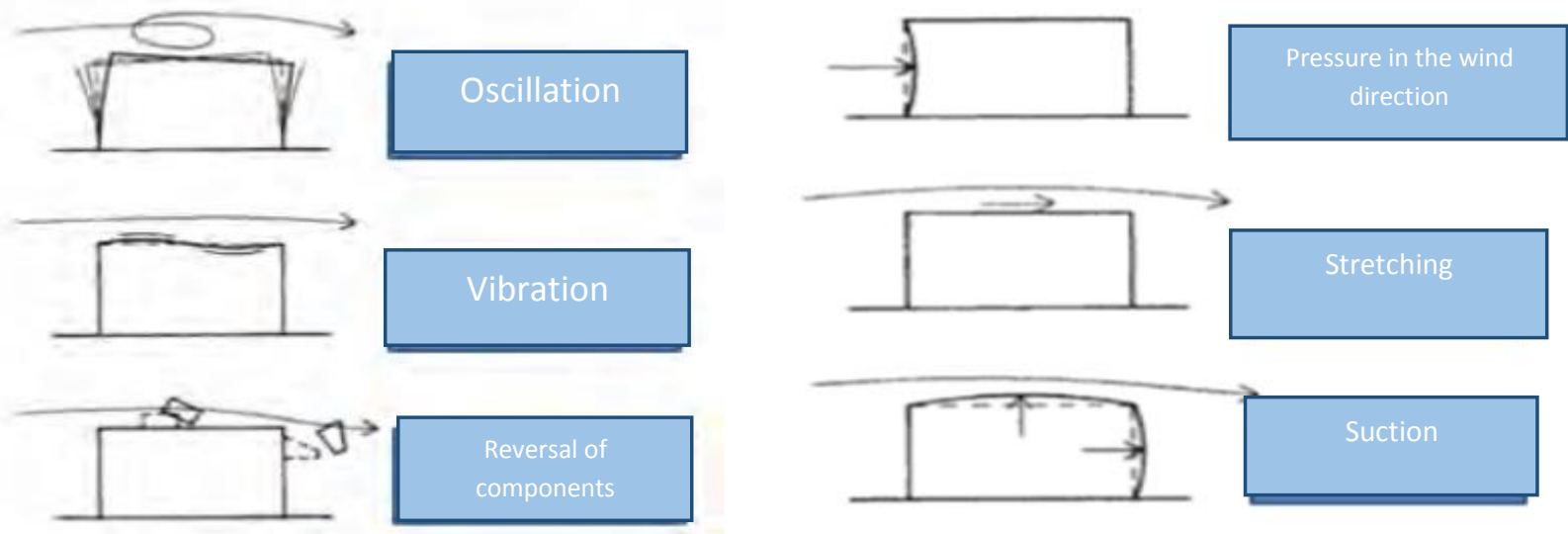

Figure 7. Effect of wind on the building

\section{The effect of wind on the outer aspects of the structure}

Other than the pressure they exert on the side exposed to the wind, the winds create suction on the opposite side and upward force on the roofs (https://www.ready.gov/tornadoes).
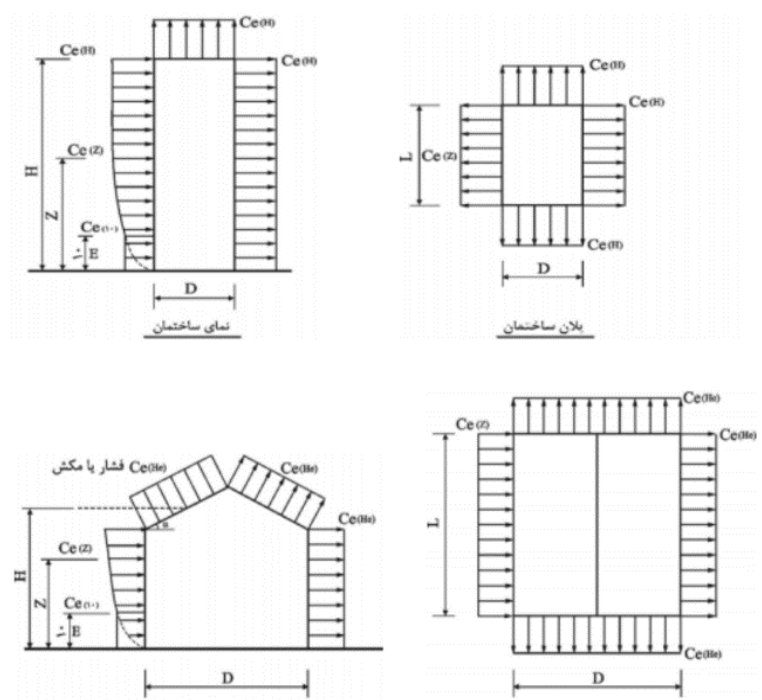

Figure 8. The effect of wind on the external walls of the building

\section{Wind-resistant building systems}

Domes, arches, and most shell forms are types of wind-resistant systems. Stabilizing the form against the wind starts with building a big base against overturning. The Transamerica building in San Francisco is an instance of this. Another issue is the ratio between the height of the building and its minimum size at the base, known as the slenderness factor. There is also a difference between the Slenderness ratio of the building mass and the effective slenderness factor, which is obtained from the effective structural lateral support mechanism. Modern high buildings add to the constraints of this slenderness factor. In such tall structures, lateral loads are more important than gravity ones.

The presence of rigid joints, shear walls, and braced frames further increase the resistance of buildings to lateral forces, like the wind. In addition to the lateral support, regardless of its type, the bracing tends to move from the center of the floor plan to the outside of the building to obtain more stability in the structural system when lateral loads increase. This practice can be completely seen in the John Hancock building in Chicago [16]. 
Tornadoes are a serious menace to buildings and inhabitants in many places. The building may be "properly built according to the rules," but that does not mean it can be protected from harsh events such as tornadoes and hurricanes. The answer is a safe room or shelter from the wind. Places, where a safe room can be built, are the basement, on top of a slab, or a concrete garage, or an interior room on the first floor.
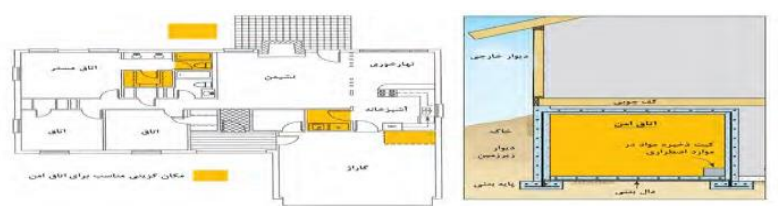

Figure 9. The correct location for the safe room

A safe room built in the basement gives maximum protection. But a safe room made in an interior room on the first floor cannot be as secure. In the basement, the safe room should be designed to limit water from accumulating through heavy rains. To build a safe room, the following points should be minded.

- Enough size to confront overturning

- Resistance to wind pressure and the penetration of objects in walls, ceilings, and doors

- Solid connection between all parts of the room for wind resistance

- Safe room walls should be able to be detached from the accommodation structure so that damage to the accommodation does not harm the safe room [17].

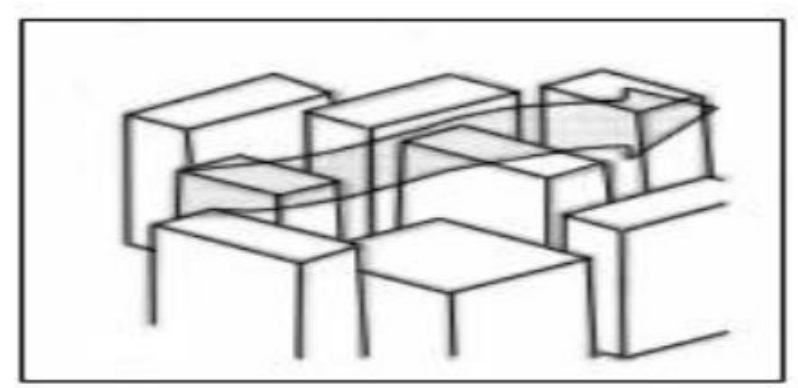

Figure 10. How the building is located

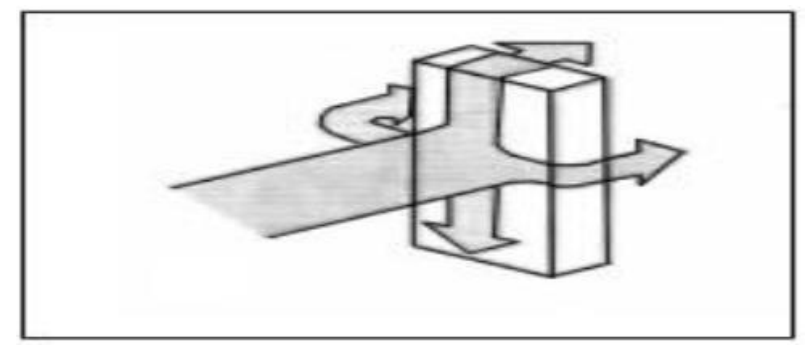

Figure 11. Better deployment

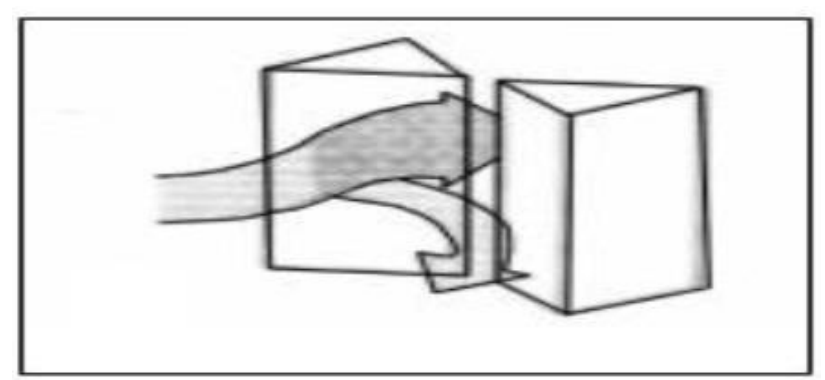

Figure 12. Influence of wind affected by the shape of the building

In spaces where, for reasons such as severe cold or heat or extreme dust, the building should be protected from very cold or very hot winds, building complexes must be designed to be compact to block the wind. In cases where high-rise buildings are created near the streets, the highest and shortest points of the building on the windward front should be in the same direction so that the airflow reaches the street level.
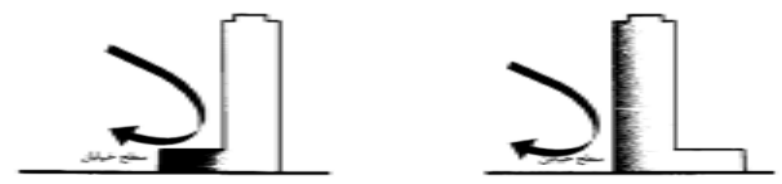

Figure 13. The highest and shortest points of the building on the windward front should be in the same direction so that the airflow reaches the street level.

\section{Site design solutions against salt storms}

It is not always possible to create outside the tidal zone. If a house or structure is in the vicinity of a tidal wave, methods to reduce tidal and hurricane damage should be considered. The best means to protect property is to build at a level higher than tidal levels. Ideally, all worthy property should be secured at a level above the height of the storm tide. To this end, one can use the slopes and heights on the site and build constructions on the hills or behind them (Figure 14).
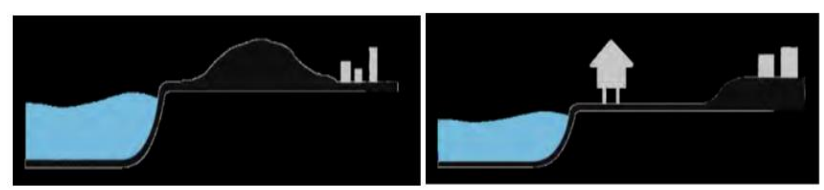

Figure 14. Building the structures on a higher level, on hills and heights, and behind the hills About the adjacent buildings, cluster and non-row layout are favored over row layout to block wind tunnels (Figure 15). 


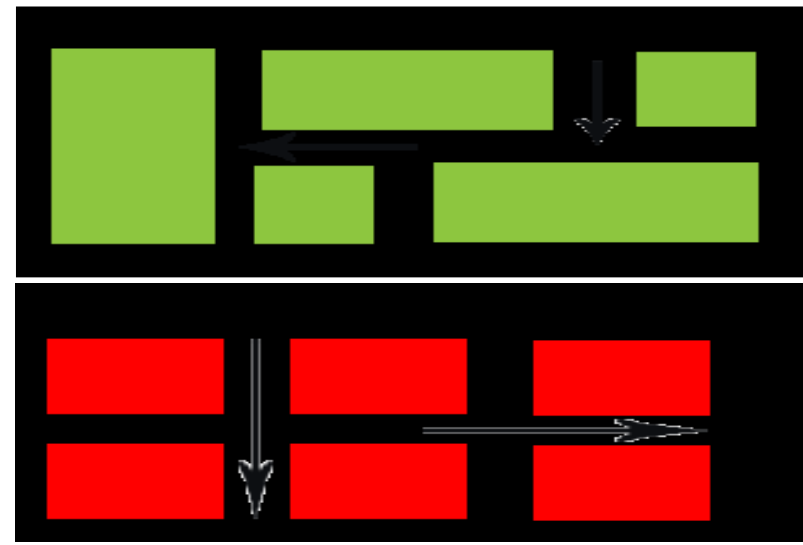

Figure 15. Avoiding wind tunnels in the cluster plan

Planting rows of trees at a distance of 8 to 10 times their height difference with buildings is another approach to decrease the risk. Minding this distance is very critical (Figure 15).
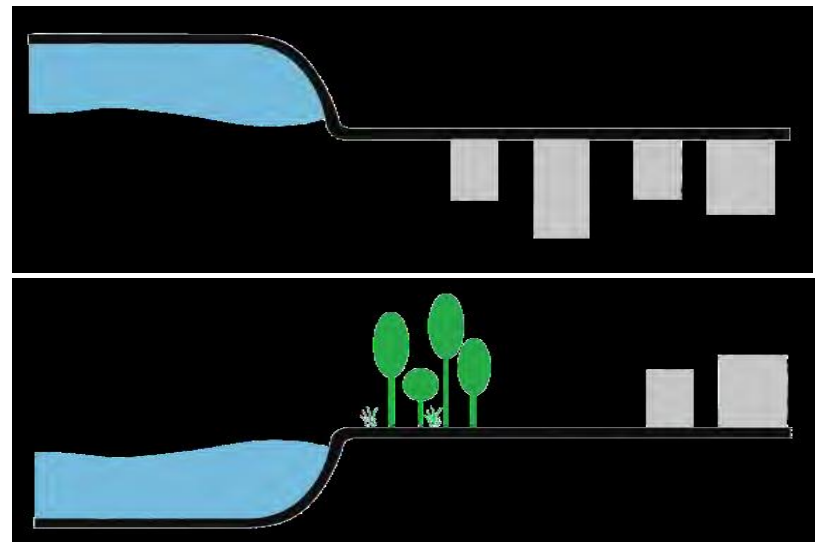

Figure 16. Planting rows of trees to guard constructions

Elements like fences, cottages, and tiny warehouses and water tanks should be set at standard distances on the site, as harsh salt storms can maximize the possibility of damaging adjacent buildings (Figure 17).
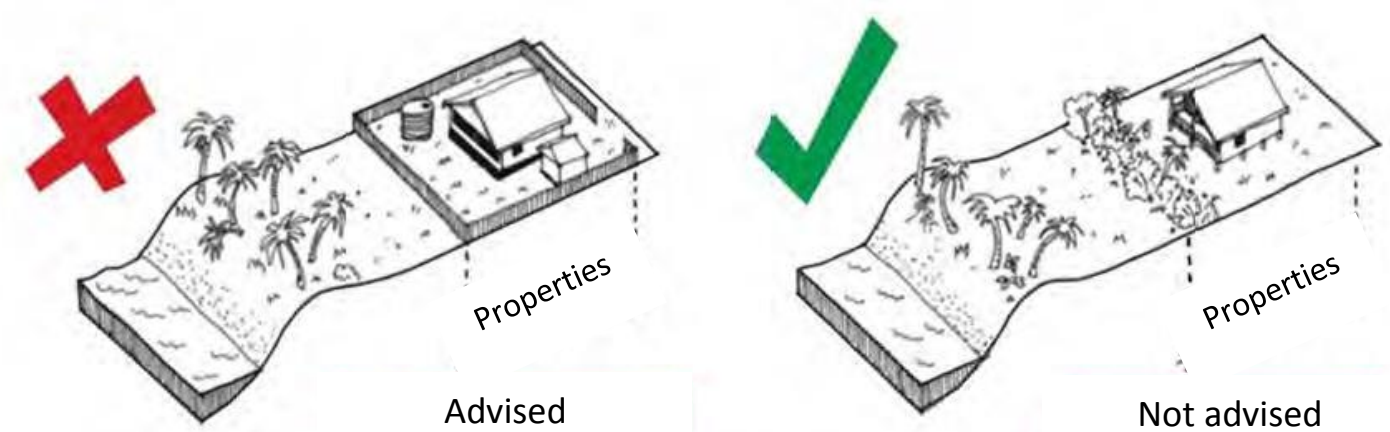

Figure 17. Avoiding the placement of site elements at non-standard distances from the building

\section{CONCLUSION}

In this study, while examining the effective factors in the decreased water level of Urmia Lake, soil salinity, environmental and ecosystem outcomes of the decrease of water in this lake were studied. excessive human interventions in the ecological cycle of the area, such as digging many wells, constructing many dams without detailed investigations, constructing the Shahid Kalantari bridge, etc., have played a notable part in causing this poor situation for Lake Urmia. The results of the research show that with the continuation of this course, the environmental and health hazards of Lake Urmia in the not too far future will change the region and encircling cities and provinces. As a result, this great national blessing will become an irreversible environmental catastrophe. With the salinities built around Lake Urmia, salt particles exposed to the air can be moved by the wind and precipitate on fertile lands. As a result, agricultural lands become unusable. Furthermore, the movement of these salts by wind and their precipitation in surface water and infiltration into groundwater yields the salinization of irrigation water. Salinity is one of the harshest environmental constraints on agricultural productivity. The use of Gum Arabic, as well as object-oriented image analysis (OBIA) techniques, is one of the latest techniques of satellite image processing in the field of remote sensing. This method, which has significant potential in soil science studies, is advised as a solution. Considering 
the answers to deal with soil salinity, building design solutions, and confronting salt storms, we concluded that buildings with a circular form have less resistance to wind and pass it easily. In areas subject to harsh storms, the number and strength of glass doors and windows should be ensured. Because these parts are quite weak and are one of the most critical factors in the storm to enter the house. Since different roofs also exhibit different resistance to storms, care must be taken in picking them. Still, every house needs a safe room that people in the home can cover in the case of an emergency. These shelters can be made in the basement, above the garage, or in a room on the first floor. Additionally, constructing houses behind natural barriers such as hills in a cluster organization, and planting trees at a proper distance around them are some of the measures that should be considered. To deal with the impacts of salt storms, designs such as dynamic capacities, fencing, etc. have been introduced that can be employed according to the studied bed.

\section{DECLARATIONS}

\section{Authors' contribution}

All the authors contributed equally to the work presented.

\section{Competing interests}

The authors declare that there is no competing interests.

\section{REFERENCES}

[1] Barzegar A (2008). Saline and Sodium Soils. First Edition. Ahwaz: Shahid Chamran University of Ahwaz.

[2] Gilfedder M, Mein RG, Connell LD (2000). Border irrigation field experiment. II: Salt transport. Journal of Irrigation and Drainage Engineering. 126(2):92-7. https://doi.org/10.1061/(ASCE)0733-9437(2000)126:2(92), Google Scholar

[3] Iranian Wetlands Protection Plan (2009). Hard Belief in the Wet Biodestruction of Wetlands, World Wetlands Day Special Issue, Bulletin No. 7.

[4] Badreldin A, Ziada A, and Blunden G. (2009). Biological Effects of Gum Arabic: A Review of Some Recent Research. Food and Chemical Toxicology, 47:
1-8. Google Scholar, https://doi.org/10.1016/j.fct.2008.07.001

[5] Bagherzadeh Karimi M, Rouhani Ravankoohi, M (2007). Guide to Iranian Wetlands Registered in Ramsar Convention, Rooz-e No Publications. Google $\underline{\text { Scholar }}$

[6] Yassin, A (2005). Water Crisis, Association of Consulting Engineers, Tehran: Hadaf Publication [in Persian].

[7] Razjouyan M (2007). Wind and Comfort, Design with Climate. Tehran, Iran: Shahid Beheshti University Publishing [In Persian] Google Scholar

[8] Alipour, H, Ghasemi Tangal Olya, H (2014). Sustainable Planning Model toward Reviving Lake Urmia, International Journal of Water Resources Development, 18 (3): 1-21. Google Scholar, https://doi.org/10.1080/07900627.2014.949636

[9] Soleimani Ziveh, M (2010). Health and Environmental Consequences of Lake Urmia Water Loss, Comparative Comparison with Similar Cases, Thirteenth National Conference on Environmental Health [in Persian].

[10] Hesami A and Amini A. (2016). Changes in irrigated land and agricultural water use in the Lake Urmia basin. Lake and Reservoir Management. 2016 Jul 2;32(3):288-96. Google Scholar, https://doi.org/10.1080/10402381.2016.1211202

[11] Metternicht G and Zinck J (2003). Remote Sensing of Soil Salinity: Potentials and Constraints. Remote Sensing of Environment, 85: 1-20. Google Scholar, https://doi.org/10.1016/So034-4257(02)00188-8

[12] Yu R, Liu T, Xu Y, Zhu C, Zhang Q, Qu Z, Liu X, and Li C (2010). Analysis of Salinization Dynamics by Remote Sensing in Hetao Irrigation District of North China. Agricultural Water Management, 97: 19521960 Google Scholar. https://doi.org/10.1016/j.agwat.2010.03.009

[13] El-Jack EMM S (2003). Effect of Gum Arabic on Some Soil Physical Properties and Growth Of Sorghum Grown On Three Soil Types. University of Khartoum. Google Scholar

[14] Whistler R, Hymowitiz T (1979). Guar Agronomy, Production, Industrial Use and Nutrition, 1-96. Google Scholar

[15] Mohammadi H, Saeedi A (2008). Effective Climatic Indicators for Assessing Human Comfort, Case Study: Qom, Journal of Environmental Science, ThirtyFourth Year, No. 47, Fall 2008.

[16] Golabchi M, Taghizadeh K, Golabchi M (2015). Construction Systems, Pars University Press. Google Scholar

[17] FEMA - K233 taking a shelter 